\title{
Some cardiovascular effects of marihuana smoking in normal volunteers
}

\begin{abstract}
Marihuana smoking caused a significant increase in heart rate in 25 normal male volunteers. The degree of techycardia was significantly related to the dose of $\Delta-9$ tetrahydrocannabinol ( $\Delta-9-T H C$ ). The marihuana smoked contained 0.5 and 2.9 per cent $\triangle-9-T H C$ and was compared to extracted marihuana as a control in a single-blind experimental design. Dose of $4-9-T H C$ was expressed as the total amount available in the number of cigarettes smoked under standard conditions. The tachycardia reached a maximum within 30 minutes and persisted longer than 90 minutes. Systolic and diastolic blood pressures were significantly elevated after total doses of marihuana containing more than $10 \mathrm{mg}$. of THC, but blood pressure was better correlated to heart rate than to dose. Changes in the electrocardiogram were minimal, but there were premature ventricular contractions in some subjects.
\end{abstract}

Stephen Johnson, M.D.,* and Edward F. Domino, M.S., M.D. Ann Arbor and Detroit, Mich.

Department of Pharmacology, University of Michigan, Ann Arbor, and Lafayette Clinic, Detroit

Many observers ${ }^{6,7}, 10$ have noted a significant dose-related increase in pulse rate in subjects smoking marihuana. While studying the effects of marihuana on the electroencephalogram (EEG) and on tests of perception and cognitive function, we observed premature ventricular contractions in 2 healthy subjects. A search of previous publications on marihuana revealed little detail about its cardiovascular effects. In view of the large number of

Supported in part by United States Public Health Service Grant MH-11846.

Received for publication May 10, 1971.

Accepted for publication July 8, 1971,

*Present address: Bernalillo County Medical Center, University of New Mexico, Albuquerque, N. M. marihuana smokers of all ages and the increasing interest in possible therapeutic uses of marihuana, we thought it important to investigate more thoroughly its cardiovascular actions.

\section{Materials and methods}

This study was performed in two parts. In 1969,10 subjects took part in a low dose $(0.5$ per cent $\Delta$-9-tetrahydrocannabinol [THC]) marihuana study and then in a single-blind placebo ( 0 per cent $\Delta-9-\mathrm{THC}$ ) study. In early 1971,15 different subjects took part in a high dose ( 2.9 per cent $\Delta-9$ THC) marihuana study. All subjects were men between the ages of 21 and 33. All had smoked marihuana previously, but only 4 
of 10 in the low-dose study and 2 of 15 in the high-dose study were daily users. One of the subjects in the high-dose study was able to tolerate a large dose $(30 \mathrm{mg}$. $\Delta-9-T H C$ ) with little change in his outward behavior or conversation. The other 14 subjects reported they were "as high or higher than ever before" during the highdose marihuana study.

The subjects received thorough medical histories, reviews of systems, and psychiatric and physical examinations. None had scores outside the normal range on the Minnesota Multiphasic Personality Inventory (MMPI). None had a history of heart disease or hypertension, nor did they have elevated blood pressure readings, irregularities of pulse, cardiac murmurs, abnormal electrocardiograms (ECG), or other evidence of cardiovascular disease on physical examination.

Marihuana was obtained from the $\mathrm{Na}$ tional Institute of Mental Health. The first batch was shown by independent analysis * to contain 0.5 per cent $\Delta-9$-tetrahydrocannabinol. Subsequently, it was found to contain $0.2 \% \Delta$-9-THC. + It was used for the low dose studies and arbitrarily assumed to contain 0.5 per cent during most of the study. A second batch of marihuana for the high dose study contained 2.9 per cent $\Delta$-9-THC. + All marihuana was administered as $300 \mathrm{mg}$. cigarettes which were smoked to the shortest possible butt. Butts were weighed to determine the approximate dose smoked. In the low-dose study, subjects smoked from 2 to 5 cigarettes. In the high-dose study, subjects were instructed to smoke until they were as high as they had ever been on marihuana and felt they could not smoke any more. This required from one to 4 cigarettes. Subjects were told to inhale deeply and to let none of the smoke appear in the exhaled

\footnotetext{
Dr. Monroe E. Wall, Director, Research Triangle Institute, Research Triangle Park, N. C.

fDr. Robert B, Forney, Prof of Pharmacology and Toxicology, Indiana University Medical Center, Indianapolis, Ind.

$¥$ Per information from Dr. Scigliano, National Institute of Mental Health.
}

air. No corrections were made for pyrolysis, exhaled smoke, and cigarette smoke burned but not inhaled.

Electrocardiograms of the 3 standard limb leads and the six chest leads were obtained in the supine position before and within $1 / 2$ hour after finishing the marihuana in 8 subjects. In 2 of the subjects, ECG's were also obtained after singleblind administration of placebo extract marihuana on which the subjects felt subjectively high and also after exercise.

Blood pressure was measured at least three times before smoking marihuana to obtain a stable base line. It was recorded three times again within $1 / 2$ hour after smoking. Diastolic pressure was recorded at the muffling of the Korotkoff sound. The difference in means of the blood pressures before and after marihuana is reported as the change in blood pressure.

Pulse rate was recorded from a continuous polygraph record in those subjects who did not have complete ECG's. The change in pulse rate is the difference between a base-line rate and the highest rate obtained within one hour of smoking marihuana.

\section{Results}

Our experiments show that the increase in heart rate after smoking marihuana is dose related (Fig. 1). The coefficient of correlation between $\log _{10}$ dose and the increase in heart rate is 0.8 for which $p<$ 0.001 . One subject, a daily user of marihuana, seemed to be extremely tolerant of the psychic effects. However, his heart rate increased from 55 to 120 after a 30 mg. dose. The marihuana-induced tachycardia persists at least 90 minutes (Fig. 2 ). The maximum heart rate was usually reached within 30 minutes after smoking the marihuana.

The systolic blood pressure was significantly elevated in subjects receiving more than $10 \mathrm{mg}$. of marihuana $(\mathrm{p}<0.01$ on the Wilcoxin sign test for differences in related samples). The rise in systolic blood pressure appeared to be dose related, although 


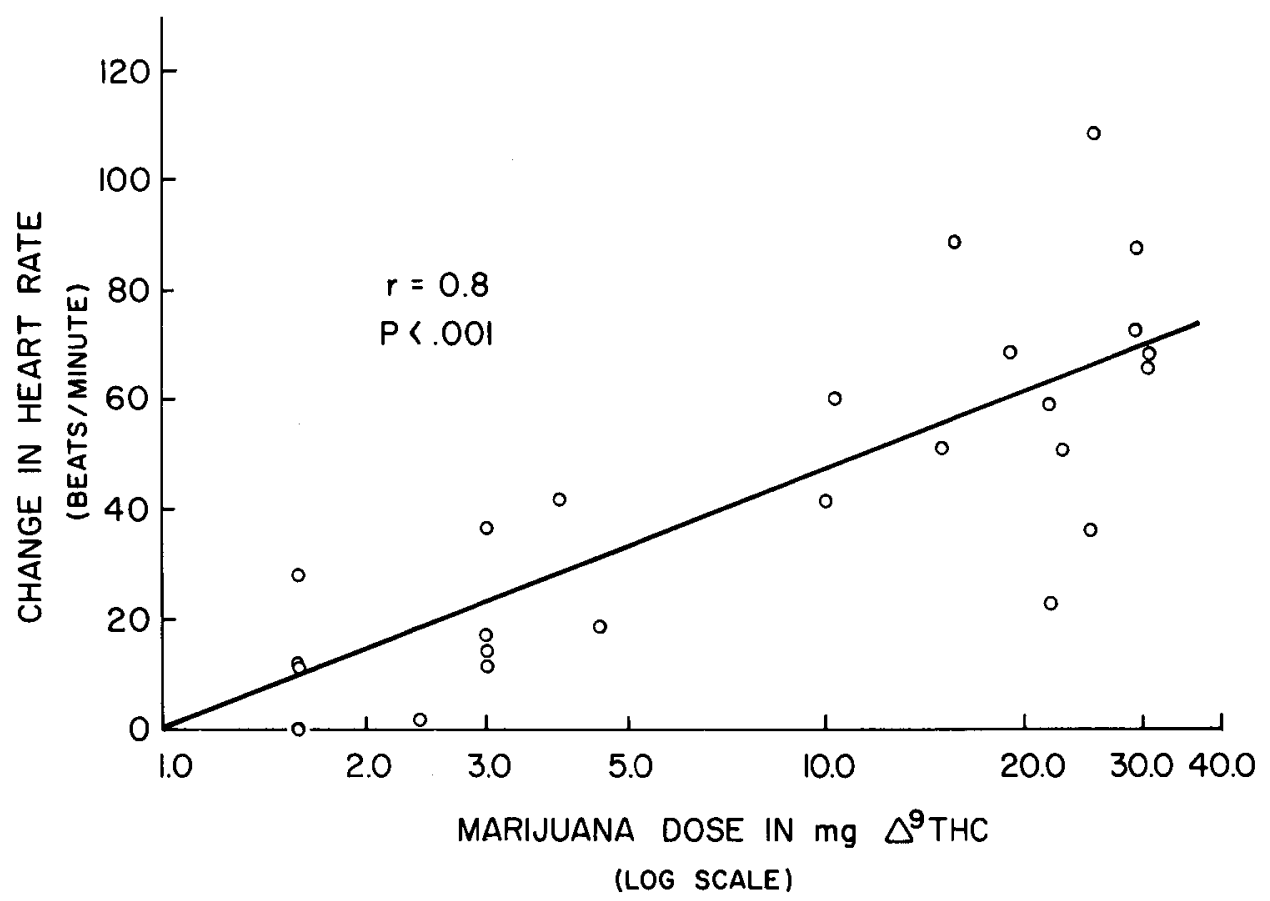

Fig. 1. Dose-effect relationship of marihuana smoking on heart rate. Adult male volunteers were given various amounts of marihuana of varying $\Delta-9-\mathrm{THC}$ content. The maximal increase in heart rate above control is given on the $\mathrm{y}$ axis and the total amount of $\Delta-9-\mathrm{THC}$ in the cigarettes on the $\mathrm{x}$ axis. Each point represents an individual subject. The coefficient of correlation is 0.8 for which $\mathrm{p}<0.001$.

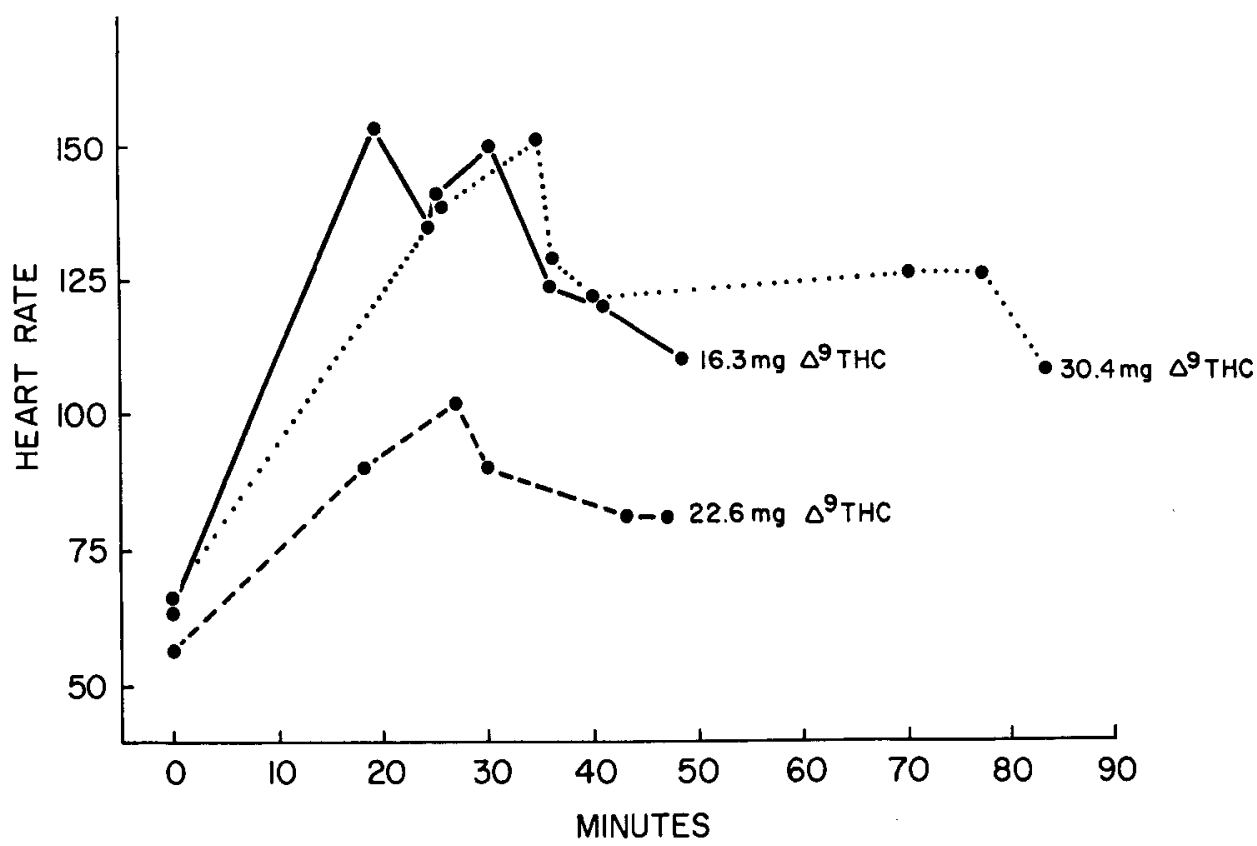

Fig. 2. Duration of marihuana-induced tachycardia in 3 different subjects. Subjects smoked varying amounts of 2.9 per cent $\Delta-9$-THC containing marihuana. Note the more prolonged heart rate increases occurred with the larger doses. 


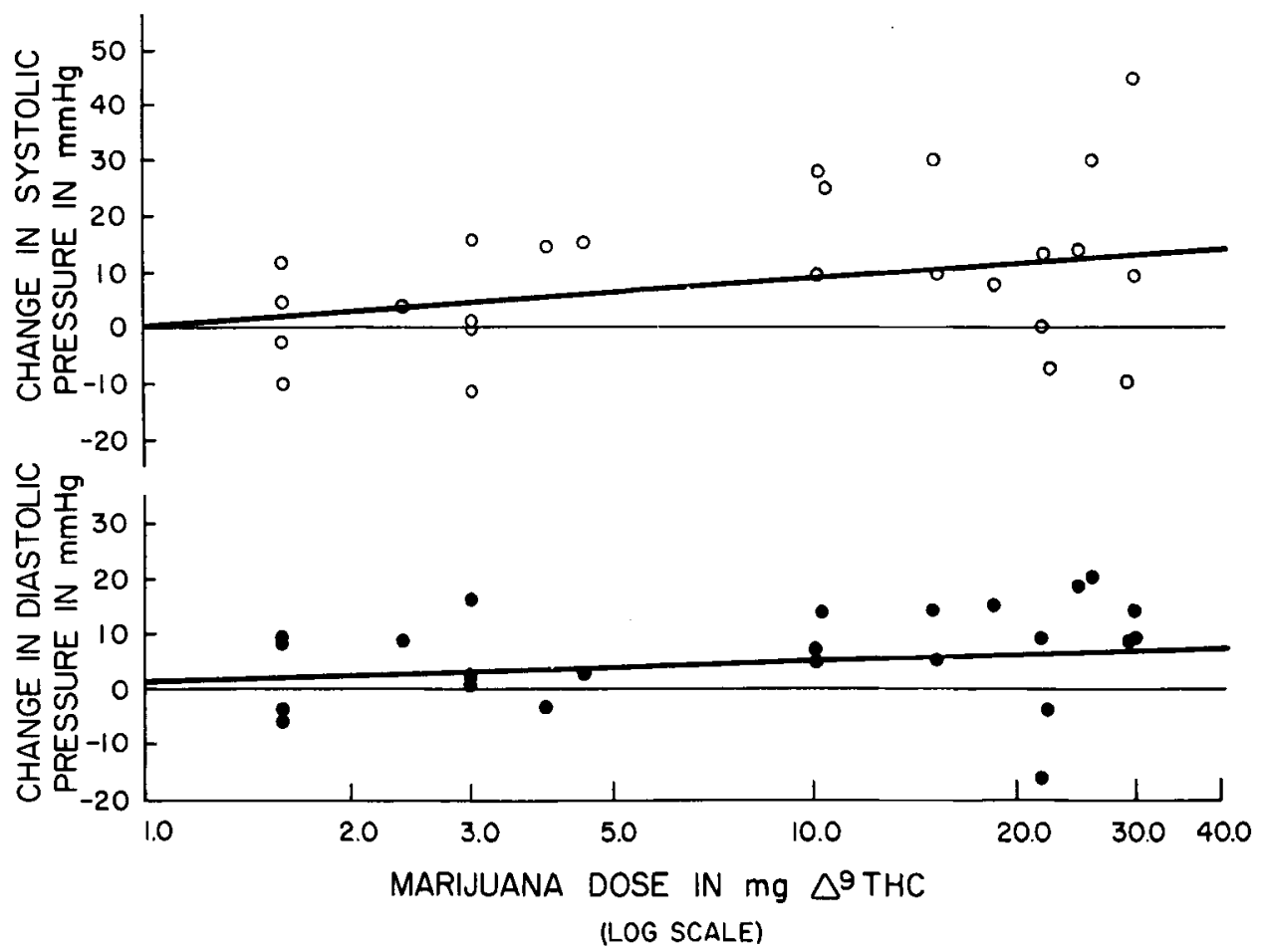

Fig. 3. Dose-effect relationship of marihuana smoking on arterial blood pressure. The upper graph illustrates the change in systolic and the lower graph the change in diastolic blood pressure. Each point represents a given subject as in Fig. 1. Note the trend for a slight increase in blood pressure which was greater for systolic than diastolic. See text for discussion of the significance of these slight changes.

the coefficient of correlation was only 0.3 and the $\mathrm{p}$ value $<0.10$. The diastolic blood pressure was also significantly elevated after marihuana smoking ( $p<0.02$ on the Wilcoxin test). For the diastolic pressure data the coefficient of correlation of the $\log _{10}$ dose response curve was only 0.3 . Systolic and diastolic blood pressure data are shown in Fig. 3.

The data from the single-blind placebo extract experiments showed no significant changes in heart rate or blood pressure.

Fig. 4 shows selected portions of Leads I, II, and $V_{5}$ of the ECG tracings, the baseline, placebo, post-15.3 mg. $\Delta-9-\mathrm{THC}$, and post-exercise results. Smoking marihuana tended to flatten $T$ waves, especially in the chest leads, in many subjects, but $T$ wave flattening was not a constant finding. $T$ wave changes induced by exercise are more prominent than those induced by the marihuana smoking. Two of 15 subjects in the high-dose study developed premature ventricular contractions (PVC's). The PVC's occurred less than 1 per 25 beats after marihuana smoking but did not appear in control ECG rhythm strips of 1 to 2 minutes in length or on control polygraph recordings. Two of the PVC's from one of the subjects are shown in Fig. 5. Besides the PVC's in 2 subjects and the tachycardia and frequent $T$ wave flattening in others, no ECG changes were noted.

\section{Discussion}

Marihuana causes a significant increase in heart rate. ${ }^{6,7,10}$ Isbell and associates ${ }^{4}$ and Hollister and associates ${ }^{3}$ have shown that $\Delta-9$-THC produces most of the psychic effects of marihuana and also the tachycardia. A recent report by Manno and associates $^{6}$ shows that the increased heart rate after marihuana is dose related. Our study also indicates a significant dose-re- 


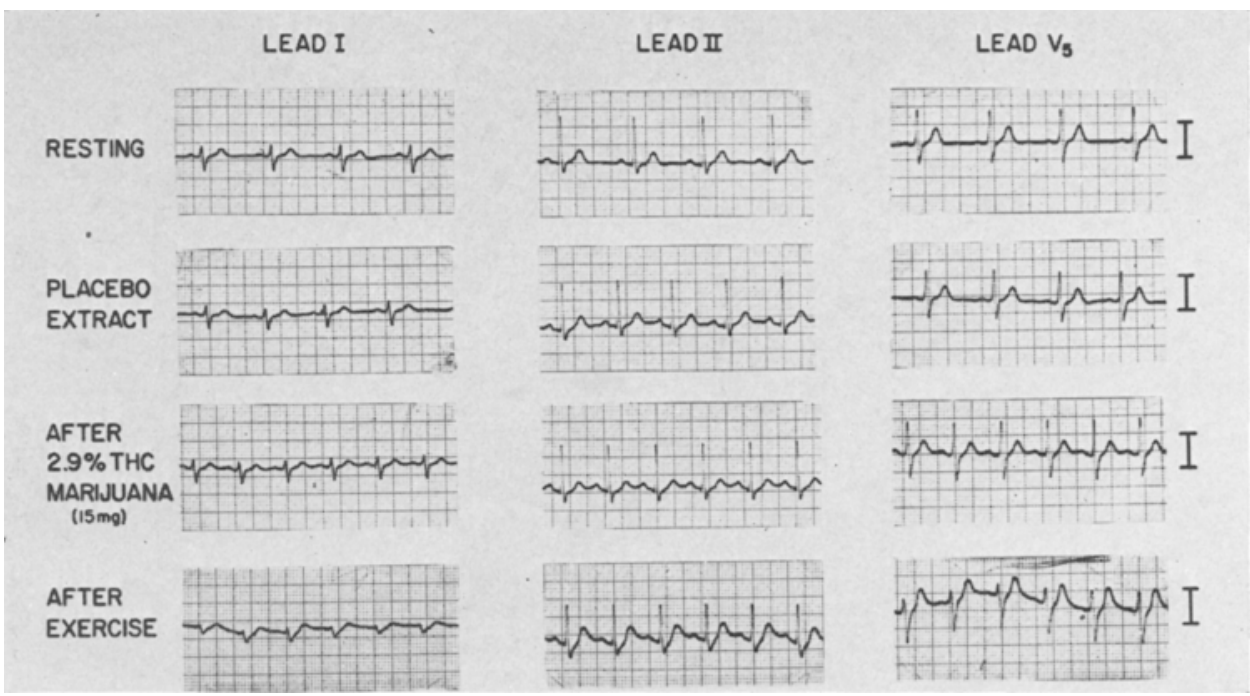

Fig. 4. ECG changes following extracted and active marihuana compared to control and exercise. A portion of each lead tracing is as shown. On different days the same subject was given $15.8 \mathrm{mg}$. of active 2.9 per cent $\Delta-9-\mathrm{THC}$ and extracted marihuana cigarettes as well as the exercise of running up a flight of stairs. Note the tachycardia after marihuana smoking compared with the tachycardia of exercise. $T$ wave changes are less marked.

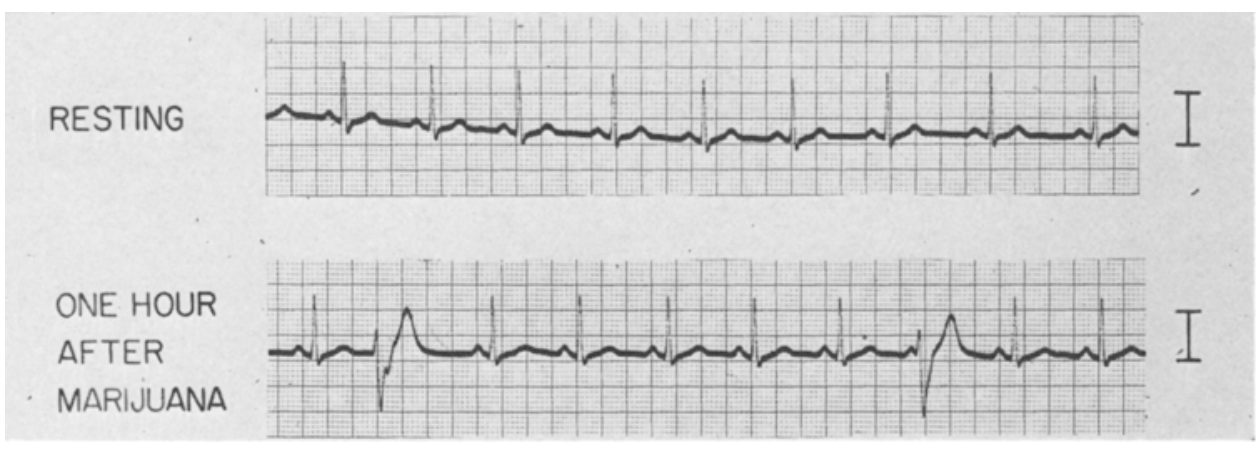

Fig. 5. Premature ventricular contractions after marihuana smoking. During the control sessions (10 min. tracing) the subject never showed PVC's but did after taking $18.9 \mathrm{mg}$. of 2.9 per cent $\Delta-9$-THC marihuana cigarettes. This particular record was taken one hour after smoking but the PVC's were seen on a polygraph record shortly after smoking as well.

sponse relationship between the $\Delta-9$-THC dose and the increased heart rate. The coefficient of correlation of 0.8 indicates that about 65 per cent of the variance in heart rate is associated with the dose of $\Delta-9$ THC in these experiments. Variability in heart rate response to a given dose could result from a number of factors. Calculation of the marihuana dosage on a milligram per kilogram basis did not reduce the variation in the data and therefore are not included as a separate table.
As indicated in the Material and Methods section, the effects of pyrolysis, ${ }^{4}$ the efficiency of absorption of smoke by the lungs, and escape of smoke from the burning cigarette were not calculated into the dose. The dose indicated in the figures is the maximum possible dose each subject could have smoked. However, we believe that the actual dose absorbed is proportional to the total dose-that is, that losses of $\Delta-9-$ THC were similar for all subjects in the study. 
A third possible explanation for variability of response at a given dose is that some subjects were tolerant to marihuana.$^{10}$ However, the one subject able to smoke 30 mg. of $\Delta-9-$ THC without feeling as high as he had ever been did have an increase of 65 beats per minute even though he seemed able to talk and reason as well as before he smoked. Hence, tolerance does not seem to develop as easily to the cardiovascular actions of marihuana as to its psychic effects. This is being pursued in another study separating subjects into tolerant and nontolerant groups.

Anxiety-producing and sedative effects of marihuana do change the magnitude of the tachycardia. This mood induced by the dose of marihuana may account for most of the variability in heart rate for a given dose. One subject, who became panicky after a $25 \mathrm{mg}$. dose of $\Delta-9-\mathrm{THC}$, had a heart rate increase of 108. Another who became somnolent after $25 \mathrm{mg}$. had a heart rate increase of only 36 .

Other investigators ${ }^{3,4,10}$ have noted variable blood pressure changes after marihuana smoking. With low doses of $\Delta-9$ THC, we noted no significant changes in blood pressure. ${ }^{9}$ At doses above $10 \mathrm{mg}$. we noted significant increases in both systolic and diastolic blood pressures. Whether the changes in blood pressure are dose related is difficult to say. The coefficients of correlation of blood pressure and log dose are low. The changes in blood pressure correlated better with tachycardia than with dose of $\Delta-9-T H C$ : for increase in heart rate versus increase in systolic pressure, $\mathrm{r}=0.381, \mathrm{p}<0.07$.

Concerning changes in the electrocardiograms, we observed premature ventricular contractions in 2 of 15 subjects receiving $10 \mathrm{mg}$. or more of marihuana. The subjects themselves were unaware of them. Flattening of $\mathrm{T}$ waves was observed, especially in the chest leads, but this was neither a constant nor a specific finding. That ECG changes are minor after marihuana agrees with the conclusions of the LaGuardia Study ${ }^{7}$ and the study by $\mathrm{Hol}_{-}$ lister and associates. ${ }^{3}$ The latter reported uniformly negative ECG's in patients who received large oral doses of $\Delta-9-\mathrm{THC}$ or pyrahexyl. This difference might indicate that the effects were related to smoking rather than to a pharmacological effect of THC.

The mechanism of the cannabis tachycardia remains unclear. The PVC's we observed may implicate catecholamine release. However, dry mouth, suggesting an atropine-like effect, and conjunctival injection, suggesting a vasodilatory action, are also present. We attempted to produce a cannabis tachycardia in an unanesthetized dog paralyzed with decamethonium. After intravenous doses of $\Delta-9$-THC from 0.32 to $3.2 \mathrm{mg}$. per kilogram we observed electroencephalographic slowing and also hypotension and bradycardia. Species differences in the cardiovascular effects and the augmentation of the tachycardia by anxiety and its reduction by sedation, suggest that the cannabis tachycardia is mediated through the central nervous system.

Although no deaths have been reported from marihuana intoxication alone, ${ }^{5}$ the tachycardia, hypertension, and PVC's it can produce indicate that marihuana should be used with caution by people with heart disease. Like nicotine and caffeine, marihuana may be a cause of PVC's in susceptible individuals. This was a relatively rare finding and may be due to smoking rather than to pure $\Delta-9-T H C$ The two susceptible subjects merely had a "before" control tracing which did not show PVC's but did “after." Further studies are clearly indicated, for marihuana smoke contains many other chemical substances. The clinical significance of our finding is probably no greater than that for susceptible subjects now smoking tobacco and drinking caffeine-containing beverages. ${ }^{2}$

\section{References}

1. Caldwell, D., Myers, S., Domino, E., and Merriam, P. E.: Auditory and visual threshold effects of marijuana in man: Addendum, Percept. Mot. Skills 29:922, 1969. 
2. Goodman, L. S., and Gilman, A., editors: The pharmacological basis of therapeutics, ed. 4, New York, 1970, The Macmillan Company, p. 1794.

3. Hollister, L. E., Richards, R. K., and Gillespie, H. K.: Comparison of tetrahydrocannabinol and synhexyl in man, Clin. Pharmacol. Ther. 9: 783-791, 1968.

4. Isbell, H., Gorodetsky, C., Jasinski, D., Claussen, V., Spulale, F., and Korte, F.: Effects of (-) $\Delta^{9}$ trans-tetrahydrocannabinol in man, Psychopharmacologia 1:184-188, 1967.

5. Jaffe, J.: Drug addiction and drug abuse, in Goodman, L. S., and Gilman, A., editors: The pharmacological basis of therapeutics, New York, 1970, The Macmillan Company.

6. Manno, J. E., Kiplinger, G. F., Haine, S. E.,
Bennett, I. F., and Forney, R. B.: Comparative effects of smoking marihuana or placebo on human motor and mental performance, CLIN. Pharmacol. Ther. 11:808-815, 1970.

7. Mayor's Committee on Marihuana: The marihuana problem in the City of New York, Lancaster, Pa., 1944, Jacques Cattell Press.

8. Pillard, R. C.: Marijuana, N. Engl. J. Med. 283:294-303, 1970.

9. Rodin, E., Domino, E., and Porzak, J.: The marijuana induced social high-Neurological and electroencephalographic concomitants, J. A. M. A. 213:1300-1302, 1970.

10. Williams, E. G., Himmelsbach, C. K., Wikler, A., Ruble, D. C., and Lloyd, Jr., B. J.: Studies on marijuana and pyrahexyl compound, Public Health Rep. 61:1059-1083, 1946. 